\section{Management in times of crisis: Can collective plans prepare teams to make and implement good decisions?}

Collective plans and managing crises

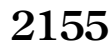

J. Lukas Thürmer

Department of Psychology, Paris Lodron University of Salzburg, Salzburg, Austria Frank Wieber

Institute of Health Sciences, Zurich University of Applied Sciences, Winterthur, Switzerland and Department of Psychology, University of Konstanz, Konstanz, Germany, and Peter M. Gollwitzer

Department of Psychology, New York University, New York, New York, USA; Department of Psychology, University of Konstanz, Konstanz, Germany and Institute of Psychology, Leuphana University Lüneburg, Lüneburg, Germany

\begin{abstract}
Purpose - Crises such as the Coronavirus pandemic pose extraordinary challenges to the decision making in management teams. Teams need to integrate available information quickly to make informed decisions on the spot and update their decisions as new information becomes available. Moreover, making good decisions is hard as it requires sacrifices for the common good, and finally, implementing the decisions made is not easy as it requires persistence in the face of strong counterproductive social pressures.

Design/methodology/approach - We provide a "psychology of action" perspective on making team-based management decisions in crisis by introducing collective implementation intentions (We-if-then plans) as a theory-based intervention tool to improve decision processes. We discuss our program of research on forming and acting on We-if-then plans in ad hoc teams facing challenging situations.

Findings - Teams with We-if-then plans consistently made more informed decisions when information was socially or temporally distributed, when decision makers had to make sacrifices for the common good, and when strong social pressures opposed acting on their decisions. Preliminary experimental evidence indicates that assigning simple We-if-then plans had similar positive effects as providing a leader to steer team processes.

Originality/value - Our analysis of self-regulated team decisions helps understand and improve how management teams can make and act on good decisions in crises such as the Coronavirus pandemic.
\end{abstract}

Keywords Collective implementation intentions, Team decisions, Causal processes, Laboratory experiments Paper type General review

(C) J. Lukas Thürmer, Frank Wieber and Peter M. Gollwitzer. Published by Emerald Publishing Limited. This article is published under the Creative Commons Attribution (CC BY 4.0) licence. Anyone may reproduce, distribute, translate and create derivative works of this article (for both commercial and noncommercial purposes), subject to full attribution to the original publication and authors. The full terms of this licence may be seen at http://creativecommons.org/licences/by/4.0/legalcode

The authors thank Anna Mayo, Johns Hopkins Carey Business School, for her helpful feedback on an earlier draft of this paper and gratefully acknowledge financial support by the German Research Foundation (DFG) through research units FOR 1882 "Psychoeconomics"; FOR 2374 "Riskdynamics" and through project 441551024 "Updating Risk". This project has received funding from the European Union's Horizon 2020 research and innovation programme under the Marie Sklodowska-Curie grant agreement No 703042 .

Received 18 August 2020 Revised 3 October 2020 19 October 2020

Accepted 19 October 2020
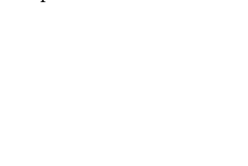
$\mathrm{MD}$

58,10

Acute crises such as the Coronavirus pandemic disrupt the way we normally do things and fundamentally change the way we work (Rudolph et al., 2020). Responses to crises may sometimes appear like a "one-person show". For instance, Prime Minister Jacinda Ardern has rightfully become associated with New Zealand's fierce and effective response to the pandemic. However, a careful analysis reveals that a key component of her leadership behavior is that she made important decisions in expert teams (Wilson, 2020). Although teams have a great potential to make good decisions, teams also exhibit decision biases (Sunstein and Hastie, 2015); especially under time pressure, when the common good requires accepting short-term individual losses, and when normative pressures arise. All these handicaps are present during crises, calling for a model of team decisions in crisis.

In developing our model, we follow recent recommendations to draw on behavioral science for crafting an effective pandemic response (Van Bavel et al., 2020). We argue that crises disrupt how teams naturally perform tasks and magnify maladaptive team processes. Teams therefore need to plan the decision process prospectively, including when, where and how to act. Our approach to management teams making decisions is akin to the approach of medical teams performing a surgery. Medical teams usually do not cut a patient open and then start looking for the tools to perform the necessary procedure. Instead, medical teams prepare all necessary equipment beforehand, including equipment for emergency procedures. Such preparation allows to respond swiftly (i.e. high speed) but also grants sufficient flexibility (i.e. performing the right procedures for the situation at hand). We suggest that management teams may psychologically prepare the mental tools necessary to make and enact good decisions during crises by forming We-if-then plans.

We will proceed as follows: First, we develop a temporal model of team decisions, including the three stages of deliberation, decision and implementation. We then analyze how crises magnify existing and yield specific challenges for decision teams. Finally, we derive a theory-based intervention to help master these challenges: We-if-then-planning (collective implementation intentions, cIIs) and review our program of research on its effectiveness.

\section{Team decisions: a "psychology of action" perspective}

A fundamental assumption that many management scientists, practitioners and the general public share is that highly motivated teams (i.e. those strongly committed) will ultimately attain their goals. This is reflected in folk wisdom such as "if there is a will, there is a way" and also in management practices, such as providing financial incentives to increase the personal value of organizational goals (Tosi et al., 2000). According to this perspective, challenges in times of crisis demand even greater commitment, akin to a hero walking through fire to accomplish the mission. There is some truth in this intuition, as those who lack commitment will hardly ever attain their goals (Sheeran, 2002), and this especially holds true when the going gets tough. However, a systematic analysis of the experimental evidence reveals that even highly committed individuals frequently fail to attain their goals (Sheeran and Webb, 2016), and this is also the case for teams (Wieber et al., 2012). A high goal commitment is thus a necessary but no sufficient condition for team goal attainment.

Accordingly, the psychology of action (Gollwitzer and Bargh, 1996; Gollwitzer and Moskowitz, 1996) assumes that committing strongly to one's goals (goal setting) is only the first step toward goal attainment. One also has to implement goal-directed actions - a process referred to as goal striving (Lewin et al., 1944; Lewin, 1926; Heckhausen and Gollwitzer, 1987). During goal striving, several challenges may arise for the individual (see Gollwitzer and Sheeran, 2006, for a detailed analysis of these challenges). As management teams are composed of many individuals, these challenges may very well also affect conjoint goal attainment (Wieber et al., 2012). Despite these parallels between individuals and teams, the specific challenges for decision teams during crises likely differ. Decision teams first deliberate the information at hand (deliberate), then decide on the basis of the available information (decide) 
and finally persistent in implementing their decision (persist, Figure 1). We argue that crises elicit a host of extraordinary challenges that all are particularly detrimental to action control at the team level, hindering teams in making and implementing good decisions (Table 1).

\section{Team decisions in times of crisis}

Management teams have to make difficult decisions (Hambrick, 1987, 2015; Tindale and Jeremy, 2020), and team decisions are highly susceptible to the impact of crises. This is because crises render natural group functioning maladaptive and traditionally prescribed remedies ineffective. Teams need to communicate effectively and coordinate their actions (Marks et al., 2001). During business-as-usual, teams are highly effective in performing these behaviors because established routines swiftly guide them (Pentland et al., 2012). Crises disrupt these routines since they fundamentally change the ways in which we work together (Mayo, 2020), thereby posing new challenges. With regard to decision teams, three challenges stand out: deliberating efficiently, deciding for the common good and persisting to implement decisions.

\section{Deliberating efficiently in times of crisis}

Crises entail a host of emerging and rapidly changing information. A common approach in such situations is to wait until all pertinent information is available, deliberate thoroughly and then make a well-informed decision. Such an approach is not possible during crises where decisions need to be made urgently (Kerrissey and Edmondson, 2020). The Coronavirus pandemic, for instance, lead to high fluctuations of the oil price, temporary factory closures and a wide application of home office. While such events show a certain coherence in hindsight, recognizing or even predicting them at the time they occur is difficult. This is because the vast body of pertinent information emerges from many different sources and over time as crises progress.

Making management decisions in teams in such critical times has the potential advantage that each team member can bring unique expertise to the table, such as economic, medical or epidemiological information. From an information processing point of view, such team decisions may yield a benefit over individual decisions as (1) members actually may learn from each other (i.e. contribute initially unshared information to the discussion) and (2) they may integrate all available information to reach a different (and better) decision than each individual alone (Schulz-Hardt and Mojzisch, 2012). Because individual members on their own lack the information to identify the optimal decision in these situations, such situations are commonly referred to as hidden profiles (Stasser et al., 1989). Regrettably, teams routinely disregard unshared information - even if they jointly discuss it (Gigone and Hastie, 1993, 1997; Mojzisch et al., 2010; Mojzisch and Schulz-Hardt, 2010) —and instead rely on what everybody already knows (i.e. shared information; Tindale and Kameda, 2000; Tindale and Sheffey, 2002). Teams thus make suboptimal decisions in hidden profile situations. These problems only intensify when teams face a wealth of information or have to decide under time

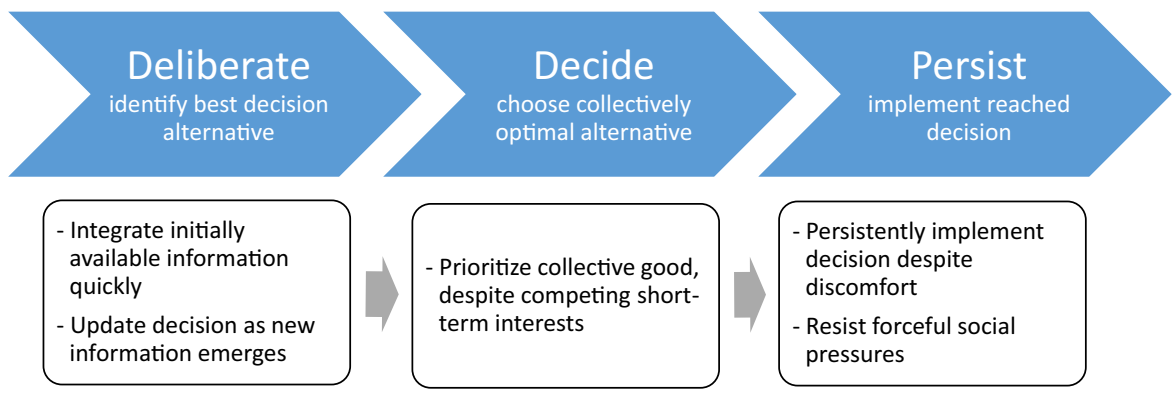

Collective plans and managing crises

\section{7}

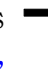


$\mathrm{MD}$

58,10

Problem

description
Empirical

evidence

Planning solution

\section{8}

Application

Deliberating: integrating socially and temporally distributed information

$1 \mathrm{a} / \mathrm{b} \quad \begin{aligned} & \text { Socially } \\ & \text { distributed } \\ & \text { informatio }\end{aligned}$

Crises require 2a/b Temporally

distributed

information
Crises develop

rapidly and new

information

emerges over

time

$\rightarrow$ Teams need

to integrate

emerging

knowledge to

decisions

Deciding: prioritizing the common good

\section{$3 \quad$ Foregoing \\ Crises lead to}

immediate

individual

financial reward

resource

scarcity, making

it hard to decide

for the common

good

$\rightarrow$ Teams need

to prioritize

collective over

self-interest
Plan to take

onlooker's

perspective

before making

decision: Allow

team to distance

from \& revise

initial decision

Plan to focus on

collective when

making decision:

Help prioritize

collective

outcome over

individual

immediate

outcome

Persisting: tolerating discomfort and withstanding social pressures

$4 \mathrm{a} / \mathrm{b}$ Implementing Crises violate decision despite basic needs, strong peer pressure

leading to

increased social
Table 1.

Overview of challenges for management teams during crises bringing

together experts

with different

backgrounds

$\rightarrow$ Teams need

to pool and

integrate unique

knowledge to

make optimal

decision

Plan to review

conflicting

information

before making

decision: Trigger

team deliberation

process to go over

new information

thoroughly

revise initial

cII "And when we

finally take the

decision sheet to

note our preferred

alternative, then

we will go over the

advantages of the

non-preferred

alternatives

again" improved

information

deliberation and

hidden profile

decisions under

time pressure in

interactive teams

cII "If we are about

to make an

investment

decision, then we

will judge the

project as neutral

observers who are

not responsible for

earlier decisions!"

reduced escalation

of commitment in

interactive teams

cII "When we are about to make our pricing decision,

then we will

consider the

collective pay-off"

increased

cooperation in

group prisoners'

dilemma game

cII "And if we

want to put

something in our

shopping basket,

pressures

$\rightarrow$ Teams need

to implement

their decisions

despite undue

social pressures
Plan to stick to necessities: Help

implement

necessary

decision swiftly,

outrunning

automatic peer

pressure ne will on take what we really need!" reduced impulse buying under strong, automatic
Plan how to revise information before making final decision during crises

Plan how to periodically objectively assess current situation during crises

Plan to focus on collective and longterm outcomes
Plan to interrupt stakeholder who is about to pressure management peer pressure 


\begin{tabular}{|c|c|c|c|c|c|c|}
\hline Exp & Problem & $\begin{array}{l}\text { Problem } \\
\text { description }\end{array}$ & Planning solution & $\begin{array}{l}\text { Empirical } \\
\text { evidence }\end{array}$ & Application & $\begin{array}{l}\text { Collective } \\
\text { plans and }\end{array}$ \\
\hline \multirow[t]{2}{*}{$5 \mathrm{a} / \mathrm{b}$} & \multirow[t]{2}{*}{$\begin{array}{l}\text { Persistent effort } \\
\text { despite } \\
\text { discomfort }\end{array}$} & \multirow{2}{*}{$\begin{array}{l}\text { Crises can last } \\
\text { for a long time, } \\
\text { requiring } \\
\text { persistent goal- } \\
\text { striving } \\
\rightarrow \text { Teams need } \\
\text { to stay on track } \\
\text { despite } \\
\text { discomfort }\end{array}$} & \multirow{2}{*}{$\begin{array}{l}\text { Plan to ignore } \\
\text { discomfort and } \\
\text { boost efficacy: } \\
\text { Overcome } \\
\text { premature signs } \\
\text { of fatigue and } \\
\text { prevent giving up } \\
\text { early }\end{array}$} & \multirow{2}{*}{$\begin{array}{l}\text { cII "And if our } \\
\text { muscles hurt, then } \\
\text { we will ignore the } \\
\text { pain and tell } \\
\text { ourselves: We can } \\
\text { do it!" improved } \\
\text { persistence in } \\
\text { physical task in } \\
\text { interactive team. } \\
\text { Increased group- } \\
\text { focused verbal } \\
\text { interaction } \\
\text { qualified as a } \\
\text { process variable }\end{array}$} & \multirow[t]{2}{*}{$\begin{array}{l}\text { Plan to ignore } \\
\text { uncomfortable } \\
\text { experiences and } \\
\text { actively use } \\
\text { motivational self- } \\
\text { speech }\end{array}$} & crises \\
\hline & & & & & & \\
\hline
\end{tabular}

Note(s): cII: Collective Implementation Intention

Table 1.

pressure (Stasser and Titus, 1987; Bowman and Wittenbaum, 2012; Lu et al., 2012; MesmerMagnus et al., 2011). Both of these challenges are common during crises.

To improve decisions in hidden profile situations, teams usually need to take their time to bring up and integrate available information. For instance, arguing for different decision alternatives (advocacy procedure) improved team information processing, at least in terms of increasing discussion intensity (Greitemeyer et al., 2006; Brian et al., 2013). Similarly, actual dissent (which may be difficult to elicit in real teams) improved hidden profile decisions by increasing discussion intensity in terms of discussion time and information elaboration (Schulz-Hardt et al., 2006). Teams during crises, however, do not have the time for such extended procedures, calling for a different approach.

Making urgent decisions in times of crisis moreover implies that the situation at hand is evolving. Management teams therefore need to systematically revise initial decisions as new information becomes available over time. For instance, during high replication rates of the Coronavirus, factory closures were crucial; as soon as the pandemic was at least somewhat under control, it became necessary to open up facilities. Even management teams that share and integrate all information at a given point in time may thus have to revise their decisions in the light of emerging information. Research indicates that teams commonly fail to heed emerging information and stick to their initial decision (i.e. escalate their commitment; Sleesman et al., 2017). One may argue that such escalation would predominantly affect inconsequential decisions. However, even medical teams were found to stick to a patient's treatment that turned out to be ineffective (Turpin et al., 2019).

One of the many processes leading to escalation of commitment (Sleesman et al., 2017) is self-justification (Staw, 1981). Accordingly, escalation of commitment alleviates the dissonance associated with admitting that an initial decision was a mistake. In line with this perspective (1) being personally responsible for the initial decision, (2) having previously expended resources (i.e. sunk cost, time invested) and (3) feeling personally threatened by the negative feedback (i.e. ego threat) all increase the escalation of commitment. In teams, these processes are particularly pronounced when each group member takes responsibility for a joint decision, leading to greater escalation than in individuals (Sleesman et al., 2017). Times of crisis pose all of these challenges, and therefore management teams in times of crisis should be particularly vulnerable to escalation of commitment.

To improve decisions in escalation of commitment situations, one may change the team leadership (Kalmanovich-Cohen et al., 2018) or introduce dissent (Greitemeyer et al., 2009). 
$\mathrm{MD}$

58,10

However, introducing further volatility by changing staff is hardly advisable during crises. And, as noted above, teams may simply lack the time for extended debates with role-play (i.e. artificial dissent) during quickly evolving crises, calling for a different approach.

\section{Deciding for the common good in times of crisis}

Even when mastering the challenge of considering all pertinent information, good decisions during crises are often hard to make. This is because scarce resources and adaptation pressures preclude continuing with business-as-usual. Good decisions in times of crisis are thus often tough decisions to make since they require putting the common good over immediate self-interests (Kerr, 1983, 2013; Van Lange et al., 2013; Bridoux and Stoelhorst, 2020). When decisions pose such an explicit conflict between collective and individual outcomes (Dawes, 1980; Messick and Brewer, 2005; Weber et al., 2004), deciding in favor of one's group (i.e. cooperating) requires self-control (Sheldon and Fishbach, 2011; Martinsson et al., 2012). Indeed, even those committed to the collective goal of securing common, longterm benefits often decide selfishly (Komorita and Parks, 1995) and shy away from uncomfortable or costly decisions, thus giving up on their own goals (Klinger, 1975). When making such decisions as a team, it becomes even harder to focus on the common good (Wildschut et al., 2003). Apparently, being part of a team makes it easier to justify greedy decisions and instills a greater fear of being exploited (Wildschut and Insko, 2007).

Such short-sighted decision making against the common good was, for example, reflected in some universities' requirement for students to return to campus during the Coronavirus pandemic (Marris, 2020). In British universities, students in lock-down apparently were not allowed to leave their dormitories, were lacking basic services such as laundromats and even had to care for their infected class-mates (Mueller, 2020). This accelerated the spread of the disease. One reason for calling students back to campus was the revenue they bring in, which many universities depend on. As one student put it: "Students are money in the bank, and as long as we're on campus they'll worry about the consequences later. (...) The financial side has taken priority over student well-being and the greater good" (Mueller, 2020).

A few interventions have shown to help teams focus on the common good. For instance, introducing interdependencies across multiple decisions makes cooperation rewarding, thereby increasing team decisions for the common good (Kugler et al., 2012). Moreover, when the situation affords the option to withdraw, groups frequently back out instead of deciding against the common good (Insko et al., 2005). During crises, however, entire industries collapse and it therefore is uncertain whether repeated interactions will be possible at all. Moreover, management teams seldom have the option to simply back out during crises, calling for a different approach.

\section{Persisting in times of crisis}

As crises play out, the implementation of good decisions requires persistence despite discomfort and rising social pressures on decision makers. Teamwork commonly supports persistence but it is also susceptible to normative influences. It is therefore likely that teams give up on their decisions once social pressures arise.

Teams are known to be highly susceptible to normative pressures especially when these come from within. Given that crises demand tough decisions, it is likely that many members of one's organization will be affected. In such situations, peers may come to "call in favors" and demand that management teams change their decisions. In fact, teams may be particularly likely to justify unethical decisions such as breaking a signed agreement (Sarah et al., 2009). For instance, a management team may be determined to restructure one's department but give up on it once observing other managers not following through.

To shield team members against strong social pressures, traditional approaches assume that teams need stronger goals to withstand them (Luo, 2005; Rook and Fisher, 1995). 
However, setting goals was found to be ineffective in reducing compliance with inappropriate requests from people one had a strong connection to (Wieber et al., 2014, Study 2; Gollwitzer et al., 2011, Study 2). Merely setting strong goals is thus unlikely to successfully counteract the strong social pressures that arise during times of crisis, calling for a different approach.

Teamwork is highly motivating when each member's contributions are clearly visible and crucial for team success (Kerr and Hertel, 2011). Accordingly, interacting groups perform better than non-interacting individuals in physical persistence tasks where effort is clearly related to performance (Köhler, 1926; Witte, 1989; see Kerr and Hertel, 2011, for review); this effect holds true in real-world action teams (Hüffmeier et al., 2017). Based on this research, one would expect that teams are well equipped to persistently endure the implementation of their decision, even during crises. However, our Psychology of Action perspective suggests that high motivation still leaves substantial team potential untapped, calling for alternative interventions.

\section{Mastering times of crisis: We-if-then plans promote good decisions}

Decision teams' natural behavior is maladaptive and traditional interventions are ineffective in times of crisis, calling for applicable alternative interventions. We argue that teams may resort to collective plans to better master the challenges of making and enacting good decisions in times of crisis. Groups seldom engage in spontaneous planning (Hackman et al., 1976) and "the processes that underlie successful planning in teams are not well understood" (DeChurch and Haas, 2008). Pointing to the potential of planning, groups in one study only capitalized on member expertise when they had planned collaboratively (Woolley et al.,2008). Our point of departure for analyzing the importance of planning in management teams during crises is a large body of individual-level research indicating that forming if-then plans or implementation intentions (IIs; Gollwitzer, 1993, 1999, 2018) helps committed individuals attain their goals (meta-analyses by Gollwitzer and Sheeran, 2006; Adriaanse et al., 2011; Bélanger-Gravel et al., 2013; Chen et al., 2015; Toli et al., 2016; Vilà et al., 2017; Silva et al., 2018; McWilliams et al., 2019; and Webb et al., 2012; meta-analysis of meta-analyses by Keller et al., 2020).

Regarding management teams, the question arises how such social entities can plan ahead. One may simply prescribe individual plans to each team member to regulate their own behavior. However, as outlined above, management teams face specific challenges during crises, casting doubt on the potential success of such an approach. Assuming that most management decisions are made by teams (Hambrick, 1987) and that making a good decision may be represented as a collective goal (Wieber et al., 2012), collective planning may the best approach to improve respective team behaviors (Thürmer et al., 2015a).

Group members can pursue collective goals (e.g. Weldon and Weingart, 1993; Kramer et al., 2013), and, when it comes to setting goals, the simple distinction between We and I can make a big difference (Mitchell and Silver, 1990; Kleingeld et al., 2011). While We-goals promote cooperative behaviors, I-goals promote the use of competitive strategies (van Mierlo and Kleingeld, 2010). We therefore argued that teams can form "We-plans" or collective implementation intentions (cIIs; e.g. "And if we encounter situation S, then we will show response R!"; Thürmer et al., 2015a) to specify when, where and how the group wants to act toward a set goal. Referring to the group in a We-if-then plan should increase focus on the group and should thereby help teams and groups to strive for their goals more effectively by promoting the key group processes of collaboration and cooperation (cf. Mayo, 2020).

Tailoring if-then plans to teams should be highly promising during crises for at least three reasons. First, making if-then plans is easy and efficient (the interventions used in the studies reported below took about $5 \mathrm{~min}$ ). Even when there is little time, teams in crisis situations can resort to if-then planning. Second, if-then planning leads to efficient action in the sense that it
Collective plans and managing crises 
helps detecting an anticipated critical situation swiftly, thereby ensuring that it is not overlooked (Parks-Stamm et al., 2007). Such efficient action control should optimize decision processes under the time constraints of a crisis. Third, if-then planning may even lead to a more automated responding by creating a strong situation-response link (McCrea et al., 2014). Such responses should help prioritize what really counts and withstand strong peer pressures, even when limited cognitive resources are available during crises.

In the following, we will report research testing the hypothesis that We-if-then planning (i.e. forming collective implementation intentions) helps teams make better decisions. As the effects of if-then plans are found to be strongest for difficult goals (Gollwitzer and Sheeran, 2006; Gollwitzer, 2014), we tested cIIs under tough conditions (e.g. time pressure, financial incentives or strong peer pressure) that are present during crises. We specifically highlight features of our studies that make them pertinent to conditions during the Coronavirus pandemic.

\section{Planning to deliberate}

We investigated whether if-then plans can help teams integrate a host of information that is socially distributed between members or temporally distributed as it only emerges over time. Regarding socially distributed information, we (Thürmer et al., 2015b) reasoned that if-then planning may help teams integrate the available information at the right time, even when time pressure calls for making a decision quickly. If-then plans help individuals break routines (Aarts et al., 1999) and deliberate about their decisions carefully (Henderson et al., 2007; Doerflinger et al., 2017). Since cIIs refer to the team, they should promote considering crucial new information (i.e. information initially uniquely held by one member) during discussions and improve decisions.

Teams of three students made four consecutive decisions in a laboratory setting (i.e. choosing an apartment, appointing a professor, selecting a shop location and hiring the best applicant for a company position). Akin to team decisions during crises, these group decisions had real-world consequences as students received a monetary bonus for each correct decision, each decision task contained a wealth of new information (45 information items), and teams had to decide under time pressure (6 min maximum). Before working on the decisions, teams took about $5 \mathrm{~min}$ to form a cII or a respective control plan. Teams randomly assigned to the cII condition specified a critical situation (coming to the point of making a decision) and a helpful strategy (reviewing all available information), and linked the two in an if-then format: "And when we finally take the decision sheet to note our preferred alternative, then we will go over the advantages of the non-preferred alternatives again." Teams in the control condition specified the same strategy but without using an if-then link: "We will go over the advantages of the non-preferred alternatives again".

Teams then worked on the first three decisions that represented so-called hidden profiles. Team members received individual information implying a suboptimal decision alternative, collectively discussed the decision and finally made a joint decision by marking their preferred option on a decision sheet. After completing the third hidden profile task, teams worked on a fourth decision task. Unbeknownst to them, unbiased information was available to each member from the onset. This way, we sought to test if our planning intervention would backfire (e.g. make teams change their optimal initial preference blindly). We recorded and coded the team discussions (Thürmer et al., 2018).

In line with our assertion that integrating socially distributed information in hidden profiles poses substantial challenges, the majority of teams did not select the optimal alternative (only $6 \%$ correct decisions). However, while none of the teams in the control condition solved any of the hidden profile problems correctly ( $0 \%$ cases solved), teams in the cII condition solved $12 \%$. Our analysis of the recorded discussions revealed that teams with 
cIIs indeed recapitulated more crucial, previously unshared information. Importantly, all teams made very good decisions in the fourth case where key information was available from the onset (control condition: 93\% correct; cII condition: 100\% correct). This indicates that planning did not make teams change their preferences blindly but to thoroughly deliberate available information. Collective planning with cIIs thus lead to better team decisions under time pressure when a wealth of information was socially distributed between team members, indicating that We-if-then plans help make informed decisions on the spot. During crises, it may moreover be tempting to follow one's gut-instincts and change decisions blindly. Importantly, cIls did not lead to such random variations but to well-justified decisions under time pressure, as indicated by high solution rates when team members' initial preference was correct (i.e. in Case 4).

Crises are evolving situations and a decision that was once prudent may later turn out to be suboptimal. Thus, even a team that shares and integrates all information at a given point in time may have to revise this decision as new information becomes available. As crises prohibit frequently changing the composition of decision teams, we tested whether collective if-then planning helps teams psychologically detach from their earlier investments and heed temporally distributed information. We reasoned that teams may find it difficult to deliberately distance themselves from their initial decision (i.e. by only forming respective goals). As if-then planning can be used to promote deep reasoning (Doerflinger et al., 2017; Martiny-Huenger et al., 2011), we argued that teams can resort to collective plans to facilitate taking an onlooker's perspective.

To test this assumption, we conducted two experimental studies with interactive teams of three students (Wieber et al., 2015a). Teams assumed the role of a city council committee steering a social investment project of building a new kindergarten (Haslam et al., 2006; see also Dietz-Uhler, 1996). Similar to crises, the project was described as urgent and unforeseen events elicited substantial threats (e.g. health hazards to children). For this task, all teams in Study 1 formed the goal "We want to make the optimal investment decision in each phase!" and, depending on random assignment, added the cII "If we are about to make an investment decision, then we will judge the project as neutral observers who are not responsible for earlier decisions!" or a self-distancing goal intention "We want to judge the project as neutral observers who are not responsible for earlier investment decisions!" (control condition). In three consecutive phases, teams then received information on the actual state of the project, discussed it and made a unanimous investment decision.

While initial information was entirely positive, later information was first mixed and then mostly negative, calling for reducing the investments over time. Team investment decisions served as the dependent measure. To disentangle the effects of goals and plans, teams in Study 2 were randomly assigned to form (1) no goal or plan, (2) only the goal intention to make optimal investment decisions or (3) this goal intention plus the cII to take an onlookers perspective (goal and cII were identical to those used in Study 1). Moreover, we made it clear that funds not invested in the current project would be available to other important projects, thus making it easier for teams to justify lower investments. Only teams that had added cIIs to their goal to make optimal investment decisions reduced their high levels of investment (Study 1) or maintained their moderate levels of investment (Study 2) in response to the emerging information. Those teams that had only formed goal intentions escalated even when they had added self-distancing goal intentions (Study 1), and they escalated as much as control teams without such a goal (Study 2).

In sum, our research findings indicate that We-if-then plans (cIIs) help both integrate socially distributed information when making initial decisions and consider conflicting temporally distributed information when revising past decisions (Wieber et al., 2015a; Thürmer et al., 2015b). For management during crises, the question arises how cIIs fare in comparison to established interventions, such as providing oversight by a leader. A recent
Collective plans and managing crises

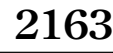


$\mathrm{MD}$

58,10

2164

experiment (Görke et al., 2020) provides preliminary evidence in this regard. Teams of four students worked on the decision tasks with socially distributed information used in our previous research, again forming either cIIs or mere goals. Moreover, one of the team members was actually a trained confederate who either served as a transactional leader (i.e. reminding team members of the task goals and the promised rewards) or merely as a notetaker. We again imposed a strict time limit and confronted teams with a wealth of information. Both cIIs and a leader improved the quality of team decisions, with no discernible difference between these interventions. Given that our cII intervention only took about 5 min and leaders commonly spend a substantial amount of time with their teams (and often receive a substantial salary), using cIIs to promote better decision making in teams seems to be the more time and cost-effective strategy.

\section{Planning to decide}

A second challenge for managing crises is that good decisions often entail personal sacrifice. This, for instance, is the case when wages and bonuses are cut or employees need to accept poor working conditions. Teams are particularly likely to abandon long-term collective goals and make selfish decisions, especially when resources become scarce and one-shot interactions prohibit continued cooperation. These conditions are present during crises, calling for interventions to help management teams focus on the common good. In individuals, if-then planning can help prioritize goals (Kirk et al., 2011; Stroebe et al., 2013) and promote actions at a personal cost (e.g. Hall et al., 2012; Trötschel and Gollwitzer, 2007; Nickerson and Rogers, 2010). Accordingly, including the collective "we" in a plan should help focus teams on collective outcomes, facilitating tough decision making in the service of the common good.

To answer these questions, we (Thürmer et al., 2020b) used a business scenario task. Similar to the conditions during crises, we introduced actual stakes (i.e. paid participants according to their decisions), substantial volatility (i.e. each decision was made with another opponent; one-shot decisions) and complete uncertainty (i.e. outcome feedback was provided after the experiment). The task posed a dilemma between a collectively profitable choice that was individually unprofitable (cooperation) and an individually profitable choice that was collectively unprofitable (defection). Importantly, participants' own business belonged to an alliance group that could earn a collective pay-off that would be equally divided between the two players. In fact, these collective pay-off matrices were constructed so that the pay-offs were identical to the individual matrices. Before working on the task, participants received a "decision training" that either contained the cII "When we are about to make our pricing decision, then we will consider the collective pay-off," the II "When I am about to make my pricing decision, then I will consider my own pay-off" or a neutral control plan, neither referring to the group nor the individual: "When the decision screen appears, then a decision has to be made." Participants then played eight rounds of the business task with other alliance group members and eight rounds of the business scenario task against strangers.

In comparison to the II and control conditions, participants with the cII to consider the group pay-off indeed cooperated more with other alliance group members. This demonstrates that cIIs can promote tough decisions in the service of the group. Participants were paid according to their decisions, and cIls thus helped participants forego some of their own payment to support the common good. Our results moreover indicate that this cooperation was strategic and only in the service of one's own group. When playing against strangers and in a structurally similar investment game that they had not planned for, no difference between conditions emerged.

Our findings are informative for team decisions in times of crisis, when decision-makers have to make sacrifices to ensure the long-term common good. At the same time, making 
sacrifices only promotes collective success if all decision-makers cooperate. It is therefore important to cooperate with one's group in the situation planned for to deter free-riders (Lewin, 1939/1997). Strategic planning with cIIs induced exactly this kind of context-specific cooperation in our experiment. On the other hand, one may argue that individual self-interest spurs collective success (Maciejovsky and Budescu, 2013; Liu et al., 2019), indicating that it would be best to only apply individual plans. However, such market effects require strong reciprocity, which may be difficult to induce during crises. Collective planning thus seems well suited to promote team decisions for the common good.

\section{Planning to persist}

During times of crisis, good decisions are not the end goal but the start of a long implementation process. This is because crises such as the Coronavirus pandemic play out over time and therefore require persistence. During this process, it is likely that stakeholders start to question decisions that are uncomfortable for them, leading to rising social pressures on management teams to give up on their decisions.

It is very difficult for management teams to persist in the face of such imminent social pressures, and the mere conviction that tough decisions are necessary will thus not be sufficient to get these decisions implemented. Individuals who form if-then plans create strong situation-response links (Wieber and Sassenberg, 2006; Martiny-Huenger et al., 2017) that trigger the specified goal-directed response (then-part) within milliseconds after encountering the critical situation specified in the if-part (Wieber et al., 2015b). In a sense, ifthen plans allow to strategically delegate action control to a situational cue (Gollwitzer, 2014). We consequently argue that forming collective if-then plans (cIIs) should help teams stick to the enactment of their decision, even when strong antagonistic social pressures arise.

We tested this prediction in the context of impulse buying decisions (Thürmer et al., 2020a, Study 1). To elicit strong social influence, we primed a group membership that commonly pressures their members into impulse buying (peer group). As a control condition, we reminded participants of a group that does not create such pressures (fellow student group). Qualitative and quantitative pretesting within the target population of undergraduates showed that peers do indeed support impulse buying (see also Luo, 2005), whereas fellow students promote being frugal. In the second part of our experiment, participants first formed a cII constituting a useful strategy in an if-then plan ("And if we want to put something in our shopping basket, then we will only take what we really need!"). To determine whether the ifthen format also contributes to cII effects, participants in two control conditions either learned the same strategy but not in an if-then format ("We will only take into our shopping basket what we really need!") or received if-then instructions containing all of the relevant words but without constituting a helpful strategy ("And if we want something that we really need, then we will put it in our basket!").

Participants then performed a hypothetical shopping task to prepare a certain dish for their respective group. Participants who had formed cIIs indeed made fewer impulse purchases (i.e. selected fewer items unrelated to the planned dish), with and without social pressure. Moreover, the if-then format further reduced impulse purchases, indicating that a strengthened associative if-then link qualifies as a psychological process underlying cII effects.

We used low-stakes decisions among highly capable undergraduates. It may therefore have been relatively easy to withstand social pressures. To rule out this alternative explanation, we conducted a large-scale correlational study with adolescents, who are especially susceptible to social pressures (Oettingen and Gollwitzer, 2015). Participants read an impulse buying scenario and indicated how they would behave as well as general
Collective plans and managing crises

2165 
$\mathrm{MD}$

58,10

questions about themselves and impulse buying. Participants' reported automatic and deliberate peer pressure (i.e. automaticity of shopping with peers and peer norms) emerged as strong predictors of impulse buying decisions in the control condition. This relation was significantly weaker in the if-then planning condition (i.e. these predictors interacted with the planning condition). If-then planning thus helped decision-makers to withstand social pressures, even when being highly vulnerable. This indicates that cIIs may even be effective when social pressures are extremely strong, such as during crises.

With regard to management decisions in crisis, the apparent effectiveness of cIIs in combating automatic social pressures is important. Automatic social pressures often go unnoticed, especially when decisions are made urgently during crises, and therefore easily derail even well-intentioned decision-makers. It might therefore not be sufficient to merely convince management teams to stay on target (i.e. increase goal commitment); to stay on track, one should additionally encourage management teams to prospectively plan how to make and implement their decisions, ideally in an if-then format.

Even when keeping social pressures in check, persistently implementing decisions during crises is uncomfortable, for instance when facing the daily hassle of wearing a face-mask. Interdependent teams are well-equipped to inspire motivation to persist in the face of such discomfort. But our action perspective suggests that even highly motivated teams may not reach their full potential. We therefore tested whether cIIs would provide an added benefit and increase physical persistence in a well-established task (Thürmer et al., 2017). Teams of three students jointly lifted a medicine ball (adapted from Bray, 2004). Team success thus depended on all members, posing a collective incentive (indispensability), and individual performance was visible, posing an individual incentive (identifiability; Kerr and Hertel, 2011). Much like common recommendations during crises (e.g. wearing face masks), holding a weight is not dangerous but it is uncomfortable (e.g. induces muscle pain) and leads to selfdoubts (e.g. exaggerated feelings of exhaustion), thereby tempting performers to give up prematurely. If-then planning can help ignore such detrimental states (Schweiger Gallo et al., 2009) and promote encouraging inner speech (Thürmer et al., 2013). We consequently expected that the cII "And if our muscles hurt, then we will ignore the pain and tell ourselves: We can do it!" as well as the II "And if my muscles hurt, then I will ignore the pain and tell myself: I can do it!" should increase team persistence. However, assuming that cIIs lead to a team focus, we expected to see differences in how team members would interact. Teams in the control groups received the same strategies suggested in either an individual or a collective goal format (i.e. "We [I] will ignore our [my] muscle pain and tell ourselves [myself]: We [I] can do it!" [individual phrasing in brackets]).

In line with our hypotheses, teams with the II and the cII improved their performance in comparison to the respective control group (mere goal strategy). Importantly, cIIs intensified team-focused communication in comparison to IIs, as indicated by the number of words spoken and references made to the team during task performance. Teams with IIs referred more to themselves (first person singular pronouns used). Both IIs and cIIs can thus support persistence in the service of the team but while IIs support individual goal striving (e.g. little and self-centered social interaction), cIIs support collective goal striving (e.g. more and teamcentered interaction). We confirmed the causal impact of these team processes in a subsequent interactive small-group experiment by manipulating communication. Teams with the cII indeed performed better when encouraged to communicate but teams with the II performed better when communication was prevented.

Key to team decisions during crises, teams with cIls took the initiative to communicate about their team. Sticking to oneself may be an effective strategy during simple physical tasks but is certainly not effective for interactive intellectual tasks, such as making management decisions. In times of crisis, the usual communication channels are blocked (e.g. no in-person meetings during lock-down), and keeping communication channels open thus 
requires the initiative of all team members (Mayo, 2020). Our research suggests that cIIs can help team members take this initiative.

\section{General discussion}

Times of crisis demand informed management decisions focused on the common good and untainted by undue social pressures. Our analysis indicates that even highly committed teams will often fail at making such good decisions in times of crisis. Fortunately, our analysis also indicates that simple We-if-then plans can contribute much to mastering this challenge. Our empirical evidence shows that teams with cIIs are more likely to (1) fully deliberate on socially or temporally distributed information, (2) decide for the common good at a personal cost and (3) persist to implement their decisions in the face of undue social pressures and discomfort. These conclusions are based on experimental evidence, providing support for the causal impact of collective plans and a host of experiments with interactive teams, providing support for the applicability of We-if-then plans in management teams.

\section{Translational impact and application}

Three key empirical questions regarding cIIs in management teams in crisis remain open: (1) Will cIIs work in management settings? (2) Will the benefits of cIIs outweigh their costs and potential risks? (3) And how can management teams form cIIs that apply to their specific situation? We have not investigated any of these questions directly but will now attempt to provide answers based on related existing research.

Implementation intention effects have been observed in a broad range of applied settings, including health behavior (Adriaanse et al., 2011; Bélanger-Gravel et al., 2013; Vilà et al., 2017) and entrepreneurial decisions (van Gelderen et al., 2017; Adam and Fayolle, 2015). Moreover, in most of our studies, we observed actual behavior that had consequences to participants' everyday life. Observing actual behavior is key to ensure the generalization from the laboratory to the field (Baumeister et al., 2010), and this is especially true for observing behavior in interacting groups (Moreland et al., 2010). Our present lab results therefore have a good chance of ultimately showing a translational impact.

The second question concerns the benefits, costs and potential risks of forming cIIs. One may argue that the effects of behavioral interventions are "too small to worry about" in management settings. However, a recent meta-analysis of meta-analyses found that if-then planning had an average effect of $d=0.54$ (Keller et al., 2020). This medium effect is comparable to the relation between firm performance and CEO pay (Tosi et al., 2000) and to assigning a leader (Görke et al., 2020). Importantly, the up-front costs of forming cIIs are small. Participants in our laboratory studies took about five minutes on average to form the required goals and plans, using simple pencil and paper methodologies. Even when assuming that an intervention in a field setting may require more explanation upfront, only minimal time-investment is needed. Concerning the risks, one may fear that if-then planning leads to rigidly following a chosen course of action. This could prove detrimental in times of crisis when the situation at hand changes rapidly. Our research, however, indicates that teams with cIIs adjusted their behavior quite flexibly: Teams with cIIs strategically cooperated only with group members and in the situation planned for, and cIls even helped revise decisions in the light of new information. This indicates that cIIs do not lead to rigidly following a set course of action.

Finally, the time needed for traditional management training formats may be lacking in times of crisis. But translating our basic research findings on if-then planning directly into large-scale interventions is no easy endeavor either (Cohen and Sherman, 2014), as one needs to make sure to reach and engage people with minimal effort. One way to achieve this would
Collective plans and managing crises 
$\mathrm{MD}$

58,10

2168

be to administer planning in questionnaires at a large scale, much like we did in most of the studies discussed in the present paper. Taking a different approach, people could develop plans tailored to their current situations and goals. To achieve this, teams could engage in mental contrasting with implementation intentions (MCII; reviews by Oettingen et al., 2013; Oettingen, 2014). Mentally contrasting a desired future with present obstacles helps identify critical situations and goal-directed behaviors (Oettingen and Mayer, 2002), which then can be linked using an if (critical situation) - then (goal-directed behavior) statement. Several intervention studies in field settings observed positive MCII effects on behavior change (e.g. Valshtein et al., 2020; Mutter et al., 2020; Loy et al., 2016). Gagné (2018) suggests that strategic planning in organizations should incorporate the principles of if-then planning by using cIIs. As the present research indicates, We-if-then planning can help teams deliberate, decide and persist to meet challenges during crises and such large-scale interventions are therefore likely to be highly successful.

\section{Theoretical implications}

On a theoretical level, our model advances the understanding of management teams during crises in at least three ways. First, our account shows how individual team members can employ their self-regulatory capabilities in the service of the team. One may argue that such effects can be explained parallel to the individual level (e.g. merely by taking into account team members' social identification). Our model goes beyond that and assumes that collective planning focuses team interactions on the team outcomes. In line with this assumption, cIIs elicited cooperation specific to one's team and team-focused interaction (Thürmer et al., 2017; Thürmer et al., 2020b). In contrast, assigning individual plans to each member of a team did not elicit such collective behavior. Second, according to recent theorizing, there may be an optimal level of uncertainty for team functioning (Griffin and Grote, 2020). Planning may enable teams to shape their environment to attain such optimal levels of uncertainty. And finally, our account highlights how teams can adaptively regulate their behavior in the face of crises. Such behavior has much in common with a characteristic referred to as resilience. As Stoverink et al. (2018) note, "[r]esilient teams need resources to identify adverse events with speed and accuracy to keep small problems from becoming major obstacles." Our theorizing would suggest that collective if-then plans are well-suited to serve this demand since they are not only effective but also efficient; they need few resource to detect critical situations and elicit the necessary responses quickly and reliably.

\section{Future research}

Our research highlights three important areas for future research. Most prominently, we have so far tested our model with interacting teams in laboratory experiments. This approach provides the gold-standard of causal evidence: Collective planning indeed improved performance! It is, however, mute to whether our model holds in field settings. Individuallevel research on if-then planning in extreme situations (van Gelderen et al., 2017) and in organizational health interventions (Lehmann et al., 2019) suggests that this should be the case. Due to the different processes at play with collective planning, future research on this question is still needed however (e.g. Lehmann et al., 2019).

We moreover observed a discontinuity between collective and individual plans, such that only collective plans promoted coordinative and cooperative behaviors (Thürmer et al., 2017) that are key for teams managing crises (Mayo, 2020). Individual-level and team-level characteristics such as problem-solving orientation (Kerrissey et al., 2020) or expertise of the group members (Mayo et al., 2019) may help teams show these behaviors, even when they do not have if-then plans. Such constructs might thus be important moderators of cII effects. 
Finally, our model so far is mute to the organizational level. In this regard, Gagné (2018) suggests that strategic planning should be carried out according to the principles of if-then planning and Grant Halvorson (2014) argues that leaders may use implementation intentions to guide their teams. An exciting program of research on so-called collaborative implementation intentions observed that involving a partner in if-then planning can promote goal attainment in the health domain (e.g. exercise; Prestwich et al., 2012; or breast self-examination; Prestwich et al., 2005). Our model suggests that such approaches could effectively prepare organizations and their teams for emerging crises, much like medical teams at the operating table.

\section{Conclusion and outlook}

In the current paper, we made the attempt to integrate two of the major areas of research fathered by Kurt Lewin, group dynamics and motivation science, with management science. This integration allowed us to identify challenges that decision teams face in times of crisis and to derive a theory-based intervention: Collective implementation intentions or, simply put, We-if-then planning. Our experimental evidence indicates that such plans causally improve team decisions. In the tradition of action research, we hope to contribute to turning scientific theory into practical wisdom. If we achieve this, responses in times of crisis will go beyond "Oh My!" and make a positive difference in the real world.

\section{References}

Aarts, H., Dijksterhuis, A.P. and Midden, C. (1999), "To plan or not to plan? Goal achievement or interrupting the performance of mundane behaviors", European Journal of Social Psychology, Vol. 29 No. 8, pp. 971-979.

Adam, A.F. and Fayolle, A. (2015), "Bridging the entrepreneurial intention-behaviour gap: the role of commitment and implementation intention", International Journal of Entrepreneurship and Small Business, Vol. 25 No. 1, pp. 36-54.

Adriaanse, M.A., Vinkers, C.D.W., De Ridder, D.T.D., Hox, J.J. and De Wit, J.B.F. (2011), "Do implementation intentions help to eat a healthy diet? A systematic review and meta-analysis of the empirical evidence", Appetite, Vol. 56, pp. 183-193, doi: 10.1016/j.appet.2010.10.012.

Baumeister, R.F., Vohs, K.D. and Funder, D.C. (2010), "Psychology as the science of self-reports and finger movements: whatever happened to actual behavior?", in Agnew, C.R., Carlston, D.E., Graziano, W.G. and Kelly, J.R. (Eds), Then a Miracle Occurs: Focusing on Behavior in Social Psychological Theory and Research, Oxford University Press, New York, NY, pp. 12-27.

Bélanger-Gravel, A., Godin, G. and Amireault, S. (2013), "A meta-analytic review of the effect of implementation intentions on physical activity", Health Psychology Review, Vol. 7 No. 1, pp. 23-54.

Bowman, J.M. and Wittenbaum, G.M. (2012), "Time pressure affects process and performance in hidden-profile groups", Small Group Research, Vol. 43 No. 3, pp. 295-314.

Bray, S.R. (2004), "Collective efficacy, group goals, and group performance of a muscular endurance task", Small Group Research, Vol. 35, pp. 230-238, doi: 10.1177/1046496403260531.

Brian, D.W., Michael, A.R. and Sukki, Y. (2013), "Uncovering hidden profiles: advocacy in team decision making", Management Decision, Vol. 51 No. 2, pp. 321-340.

Bridoux, F. and Stoelhorst, J.W. (2020), "Stakeholder governance: solving the collective action problems in joint value creation", Academy of Management Review, in press, Online-First Article.

Chen, X.J., Wang, Y., Liu, L.-L., Cui, J.F., Gan, M.-Y., Shum, D.H.K. and Chan, R.C. (2015), “The effect of implementation intention on prospective memory: a systematic and meta-analytic review", Psychiatry Research, Vol. 226, pp. 14-22, doi: 10.1016/j.psychres.2015.01.011. 
Cohen, G.L. and Sherman, D.K. (2014), "The psychology of change: self-affirmation and social psychological intervention", Annual Review of Psychology, Vol. 65 No. 1, pp. 333-371.

Dawes, R.M. (1980), "Social dilemmas”, Annual Review of Psychology, Vol. 31, pp. 169-193.

DeChurch, L.A. and Haas, C.D. (2008), "Examining team planning through an episodic lens", Small Group Research, Vol. 39 No. 5, pp. 542-568.

Dietz-Uhler, B. (1996), "The escalation of commitment in political decision-making groups: a social identity approach", European Journal of Social Psychology, Vol. 26, pp. 611-629.

Doerflinger, J.T., Martiny-Huenger, T. and Gollwitzer, P.M. (2017), "Planning to deliberate thoroughly: if-then planned deliberation increases the adjustment of decisions to newly available information”, Journal of Experimental Social Psychology, Vol. 69 No. 1, pp. 1-12.

Gagné, M. (2018), "From strategy to action: transforming organizational goals into organizational behavior", International Journal of Management Reviews, Vol. 20 No. S1, pp. S83-S104.

Gigone, D. and Hastie, R. (1993), "The common knowledge effect: information sharing and group judgment”, Journal of Personality and Social Psychology, Vol. 65, pp. 959-974, doi: 10.1037/00223514.65.5.959.

Gigone, D. and Hastie, R. (1997), "The impact of information on small group choice", Journal of Personality and Social Psychology, Vol. 72, pp. 132-140, doi: 10.1037/0022-3514.72.1.132.

Gollwitzer, P.M. (1993), "Goal achievement: the role of intentions", European Review of Social Psychology, Vol. 4 No. 1, pp. 141-185.

Gollwitzer, P.M. (1999), "Implementation intentions: strong effects of simple plans", American Psychologist, Vol. 54 No. 7, pp. 493-503.

Gollwitzer, P.M. (2014), "Weakness of the will: is a quick fix possible?", Motivation and Emotion, Vol. 38 No. 3, pp. 305-322.

Gollwitzer, P.M. (2018), "The goal concept: a helpful tool for theory development and testing in motivation science", Motivation Science, Vol. 4 No. 3, pp. 185-205.

Gollwitzer, P.M. and Bargh, J.A. (1996), The Psychology of Action: Linking Cognition and Motivation to Behavior, Guilford Press, New York, NY.

Gollwitzer, P.M. and Moskowitz, G.B. (1996), "Goal effects on action and cognition", in Higgins, E.T. and Kruglanski, A.W. (Eds), Social Psychology: Handbook of Basic Principles, Guilford Press, New York, NY, pp. 361-399.

Gollwitzer, P.M. and Sheeran, P. (2006), "Implementation intentions and goal achievement: a metaanalysis of effects and processes", in Zanna, M.P. (Ed.), Advances in Experimental Social Psychology, Elsevier Academic Press, San Diego, CA, pp. 69-119.

Gollwitzer, P.M., Sheeran, P., Trötschel, R. and Webb, T.L. (2011), "Self-regulation of priming effects on behavior", Psychological Science, Vol. 22, pp. 901-907, doi: 10.1177/0956797611411586.

Görke, L., Thürmer, J.L., Kunze, F. and Gollwitzer, P.M. (2020), "How task-focused leadership and implementation intentions improve team decisions in hidden profiles", unpublished manuscript, University of Konstanz, Konstanz.

Grant Halvorson, H. (2014), "Get your team to do what it says it's going to do", Harvard Business Review, Vol. 92 No. 5, pp. 82-87.

Greitemeyer, T., Schulz-Hardt, S., Brodbeck, F.C. and Frey, D. (2006), "Information sampling and group decision making: the effects of an advocacy decision procedure and task experience", Journal of Experimental Psychology: Applied, Vol. 12, pp. 31-42, doi: 10.1037/1076-898x.12.1.31.

Greitemeyer, T., Schulz-Hardt, S. and Frey, D. (2009), "The effects of authentic and contrived dissent on escalation of commitment in group decision making", European Journal of Social Psychology, Vol. 39 No. 4, pp. 639-647.

Griffin, M.A. and Grote, G. (2020), "When is more uncertainty better? A model of uncertainty regulation and effectiveness", Academy of Management Review, Online First Article. 
Hackman, J.R., Brousseau, K.R. and Weiss, J.A. (1976), "The interaction of task design and group performance strategies in determining group effectiveness", Organizational Behavior and Human Performance, Vol. 16 No. 2, pp. 350-365.

Hall, P.A., Zehr, C.E., Ng, M. and Zanna, M.P. (2012), "Implementation intentions for physical activity in supportive and unsupportive environmental conditions: an experimental examination of intention-behavior consistency", Journal of Experimental Social Psychology, Vol. 48, pp. 432-436, doi: 10.1016/j.jesp.2011.09.004.

Hambrick, D.C. (1987), “The top management team: key to strategic success”, California Management Review, Vol. 30 No. 1, pp. 88-108.

Hambrick, D.C. (2015), "Top management teams", in Flood, P.C. and Freeney, Y. (Eds), Wiley Encyclopedia of Management, John Wiley \& Sons, Chichester, p. 23.

Haslam, S.A., Ryan, M.K., Postmes, T., Spears, R., Jetten, J. and Webley, P. (2006), "Sticking to our guns: social identity as a basis for the maintenance of commitment to faltering organizational projects", Journal of Organizational Behavior, Vol. 27, pp. 607-628.

Heckhausen, H. and Gollwitzer, P.M. (1987), "Thought contents and cognitive functioning in motivational versus volitional states of mind", Motivation and Emotion, Vol. 11 No. 2, pp. 101-120.

Henderson, M.D., Gollwitzer, P.M. and Oettingen, G. (2007), "Implementation intentions and disengagement from a failing course of action", Journal of Behavioral Decision Making, Vol. 20 No. 1, pp. 81-102.

Hüffmeier, J., Filusch, M., Mazei, J., Hertel, G., Mojzisch, A. and Krumm, S. (2017), "On the boundary conditions of effort losses and effort gains in action teams", Journal of Applied Psychology, Vol. 102, pp. 1673-1685, doi: 10.1037/ap10000245.

Insko, C.A., Kirchner, J.L., Pinter, B., Efaw, J. and Wildschut, T. (2005), "Interindividual-intergroup discontinuity as a function of trust and categorization: the paradox of expected cooperation", Journal of Personality and Social Psychology, Vol. 88, pp. 365-385, doi: 10.1037/0022-3514.88.2.365.

Kalmanovich-Cohen, H., Pearsall, M.J. and Christian, J.S. (2018), "The effects of leadership change on team escalation of commitment", The Leadership Quarterly, Vol. 29 No. 5, pp. 597-608.

Keller, L., Gollwitzer, P.M. and Sheeran, P. (2020), "Changing behavior using the model of action phases", in Hagger, M.S., Cameron, L., Hamilton, K., Hankonen, N. and Lintunen, T. (Eds), The Handbook of Behavior Change, Cambridge University Press, Cambridge, pp. 77-88.

Kerr, N.L. (1983), "Motivation losses in small groups: a social dilemma analysis", Journal of Personality and Social Psychology, Vol. 45 No. 4, pp. 819-828.

Kerr, N.L. (2013), "Social dilemmas", in Levine, J.M. (Ed.), Group Processes, Psychology Press, New York, NY, pp. 85-110.

Kerr, N.L. and Hertel, G. (2011), “The Köhler group motivation gain: how to motivate the 'weak links' in a group", Social and Personality Psychology Compass, Vol. 5 No. 1, pp. 43-55.

Kerrissey, M.J. and Edmondson, A.C. (2020), "What good leadership looks like during this pandemic", Harvard Business Review, Vol. 13 No. 1.

Kerrissey, M.J., Mayo, A.T. and Edmondson, A.C. (2020), "Joint problem-solving orientation in fluid cross-boundary teams", Academy of Management Discoveries, Online-First Article, doi: 10.5465/ amd.2019.0105.

Kirk, D., Gollwitzer, P.M. and Carnevale, P.J. (2011), "Self-regulation in ultimatum bargaining: goals and plans help accepting unfair but profitable offers", Social Cognition, Vol. 29 No. 5, pp. 528-546.

Kleingeld, A., van Mierlo, H. and Arends, L. (2011), "The effect of goal setting on group performance: a meta-analysis", Journal of Applied Psychology, Vol. 96 No. 6, pp. 1289-1304.

Klinger, E. (1975), "Consequences of commitment to and disengagement from incentives", Psychological Review, Vol. 82 No. 1, pp. 1-25. 
Köhler, O. (1926), "Kraftleistungen bei Einzel- und Gruppenabeit", Industrielle Psychotechnik, Vol. 3, pp. 274-282.

Komorita, S.S. and Parks, C.D. (1995), "Interpersonal relations: mixed-motive interaction", Annual Review of Psychology, Vol. 46 No. 1, pp. 183-207.

Kramer, W.S., Thayer, A.L. and Salas, E. (2013), "Goal setting in teams", in Locke, E.A. and Latham, G.P. (Eds), New Developments in Goal Setting and Task Performance, Routledge/Taylor \& Francis Group, New York, NY, pp. 287-310.

Kugler, T., Kausel, E.E. and Kocher, M.G. (2012), "Are groups more rational than individuals? A review of interactive decision making in groups", Wiley Interdisciplinary Reviews: Cognitive Science, Vol. 3 No. 4, pp. 471-482.

Lehmann, A.I., Brauchli, R. and Bauer, G.F. (2019), "Goal pursuit in organizational health interventions: the role of team climate, outcome expectancy, and implementation intentions", Frontiers in Psychology, Vol. 10 No. 154.

Lewin, K. (1926), "Vorsatz, Wille und Bedürfnis”, Psychologische Forschung, Vol. 7 No. 1, pp. 330-385.

Lewin, K. (1939/1997), "When facing danger (1939)", Resolving Social Conflicts and Field Theory in Social Science, American Psychological Association, Washington, DC, pp. 116-121.

Lewin, K., Dembo, T., Festinger, L. and Sears, P.S. (1944), "Level of aspiration”, in Hunt, J.M. (Ed.), Personality and the Behavior Disorders, Ronald Press, Oxford, pp. 333-378.

Liu, M.-L., Lin, C.-P., Joe, S.-W. and Chen, K.-J. (2019), "Modeling knowledge sharing and team performance: the interactions of ethical leadership and ambidexterity with politics and job complexity”, Management Decision, Vol. 57, pp. 1472-1495, doi: 10.1108/MD-01-2017-0052.

Loy, L.S., Wieber, F., Gollwitzer, P.M. and Oettingen, G. (2016), "Supporting sustainable food consumption: mental contrasting with implementation intentions (MCII) aligns intentions and behavior", Frontiers in Psychology, Vol. 7, doi: 10.3389/fpsyg.2016.00607.

Lu, L., Yuan, Y.C. and McLeod, P.L. (2012), "Twenty-five years of hidden profiles in group decision making", Personality and Social Psychology Review, Vol. 16 No. 1, pp. 54-75.

Luo, X. (2005), "How does shopping with others influence impulsive purchasing?", Journal of Consumer Psychology, Vol. 15 No. 4, pp. 288-294.

Maciejovsky, B. and Budescu, D.V. (2013), "Markets as a structural solution to knowledge-sharing dilemmas", Organizational Behavior and Human Decision Processes, Vol. 120 No. 2, pp. 154-167.

Marks, M.A., Mathieu, J.E. and Zaccaro, S.J. (2001), "A temporally based framework and taxonomy of team processes", The Academy of Management Review, Vol. 26 No. 3, pp. 356-376.

Marris, E. (2020), "The giant university COVID experiment”, Nature, Vol. 584, pp. 510-512.

Martinsson, P., Myrseth, K.O.R. and Wollbrant, C. (2012), "Reconciling pro-social vs. selfish behavior: on the role of self-control", Judgment \& Decision Making, Vol. 7 No. 3, pp. 1-20.

Martiny-Huenger, T., Thürmer, J.L., Issa, M. and Gollwitzer, P.M. (2011), "Über die Unterstützung reflektiver Verhaltensdeterminanten”, Psychologische Rundschau, Vol. 62, pp. 179-187, doi: 10. 1026/0033-3042/a000087.

Martiny-Huenger, T., Martiny, S.E., Parks-Stamm, E.J., Pfeiffer, E. and Gollwitzer, P.M. (2017), "From conscious thought to automatic action: a simulation account of action planning", Journal of Experimental Psychology: General, Vol. 146, pp. 1513-1525, doi: 10.1037/xge0000344.

Mayo, A.T. (2020), "Teamwork in a pandemic: insights from management research", BMJ Leader. doi: 10.1136/leader-2020-000246.

Mayo, A.T., Woolley, A.W. and Chow, R.M. (2019), “Unpacking participation and influence: diversity's countervailing effects on expertise use in groups", Academy of Management Discoveries, Vol. 6 No. 2, pp. 300-319.

McCrea, S.M., Penningroth, S.L. and Radakovich, M.P. (2014), "Implementation intentions forge a strong cue-response link and boost prospective memory performance", Journal of Cognitive Psychology, Vol. 27 No. 1, pp. 12-26. 
McWilliams, L., Bellhouse, S., Yorke, J., Lloyd, K. and Armitage, C.J. (2019), “Beyond 'planning': a meta-analysis of implementation intentions to support smoking cessation", Health Psychology, Vol. 38, pp. 1059-1068, doi: 10.1037/hea0000768.

Mesmer-Magnus, J.R., DeChurch, L.A., Jimenez-Rodriguez, M., Wildman, J. and Shuffler, M. (2011), “A meta-analytic investigation of virtuality and information sharing in teams", Organizational Behavior and Human Decision Processes, Vol. 115, pp. 214-225, doi: 10.1016/j.obhdp.2011.03.002.

Collective plans and managing crises

2173

Messick, D.M. and Brewer, M.B. (2005), "Solving social dilemmas: a review", in Bazerman, M.H. (Ed.), Negotiation, Decision Making and Conflict Management, Edward Elgar Publishing, Northampton, MA, pp. 98-131.

Mitchell, T.R. and Silver, W.S. (1990), "Individual and group goals when workers are interdependent: effects on task strategies and performance", Journal of Applied Psychology, Vol. 75 No. 2, pp. 185-193.

Mojzisch, A. and Schulz-Hardt, S. (2010), "Knowing others' preferences degrades the quality of group decisions", Journal of Personality and Social Psychology, Vol. 98, pp. 794-808, doi: 10.1037/ a0017627.

Mojzisch, A., Grouneva, L. and Schulz-Hardt, S. (2010), "Biased evaluation of information during discussion: disentangling the effects of preference consistency, social validation, and ownership of information”, European Journal of Social Psychology, Vol. 40, pp. 946-956, doi: 10.1002/ ejsp.660.

Moreland, R.L., Fetterman, J.D., Flagg, J.J. and Swanenburg, K.L. (2010), "Behavioral assessment practices among social psychologists who study small groups", in Agnew, C.R., Carlston, D.E., Graziano, W.G. and Kelly, J.R. (Eds), Then a Miracle Occurs: Focusing on Behavior in Social Psychological Theory and Research, Oxford University Press, New York, NY, pp. 28-53.

Mueller, B. (2020) "British universities reopen with students locked down and forced to care for infected classmates", New York Times.

Mutter, E.R., Oettingen, G. and Gollwitzer, P.M. (2020), "An online randomised controlled trial of mental contrasting with implementation intentions as a smoking behaviour change intervention", Psychology and Health, Vol. 35, pp. 318-345, doi: 10.1080/08870446.2019.1634200.

Nickerson, D.W. and Rogers, T. (2010), "Do you have a voting plan?”, Psychological Science, Vol. 21, pp. 194-199, doi: 10.1177/0956797609359326.

Oettingen, G. (2014), Rethinking Positive Thinking: Inside the New Science of Motivation, Penguin, New York, NY.

Oettingen, G. and Gollwitzer, P.M. (2015), Self-regulation in Adolescence, Cambridge University Press, New York, NY.

Oettingen, G. and Mayer, D. (2002), "The motivating function of thinking about the future: expectations versus fantasies", Journal of Personality and Social Psychology, Vol. 83 No. 5, pp. 1198-1212.

Oettingen, G., Wittchen, M. and Gollwitzer, P.M. (2013), "Regulating goal pursuit through mental contrasting with implementation intentions", in Locke, E.A. and Latham, G.P. (Eds), New Developments in Goal Setting and Task Performance, Routledge, New York, NY, pp. 523-548.

Parks-Stamm, E.J., Gollwitzer, P.M. and Oettingen, G. (2007), "Action control by implementation intentions: effective cue detection and efficient response initiation", Social Cognition, Vol. 25 No. 2, pp. 248-266.

Pentland, B.T., Feldman, M.S., Becker, M.C. and Liu, P. (2012), "Dynamics of organizational routines: a generative model”, Journal of Management Studies, Vol. 49, pp. 1484-1508, doi: 10.1111/j.14676486.2012.01064.x.

Prestwich, A., Conner, M., Lawton, R., Bailey, W., Litman, J. and Molyneaux, V. (2005), "Individual and collaborative implementation intentions and the promotion of breast self-examination", Psychology and Health Education Research, Vol. 20, pp. 743-760, doi: 10.1080/ 14768320500183335 . 
$\mathrm{MD}$

58,10

Prestwich, A., Conner, M.T., Lawton, R.J., Ward, J.K., Ayres, K. and McEachan, R.R.C. (2012), "Randomized controlled trial of collaborative implementation intentions targeting working adults' physical activity", Health Psychology, Vol. 31 No. 4, pp. 486-495, doi: 10.1037/a0027672.

Rook, D.W. and Fisher, R.J. (1995), "Normative influences on impulsive buying behavior”, Journal of Consumer Research, Vol. 22 No. 3, pp. 305-313.

Rudolph, C.W., Allan, B., Clark, M., Hertel, G., Hirschi, A., Kunze, F., Shockley, K., Shoss, M., Sonnentag, S. and Zacher, H. (2020), "Pandemics: implications for research and practice in industrial and organizational psychology", Industrial and Organizational Psychology, OnlineFirst Article.

Sarah, S., Scott, T.R. and Amanda, D.E. (2009), "The effects of ethical climate on group and individual level deception in negotiation", International Journal of Conflict Management, Vol. 20 No. 3, pp. 287-308.

Schulz-Hardt, S. and Mojzisch, A. (2012), "How to achieve synergy in group decision making: lessons to be learned from the hidden profile paradigm", European Review of Social Psychology, Vol. 23 No. 1, pp. 305-343.

Schulz-Hardt, S., Brodbeck, F.C., Mojzisch, A., Kerschreiter, R. and Frey, D. (2006), "Group decision making in hidden profile situations: dissent as a facilitator for decision quality", Journal of Personality and Social Psychology, Vol. 91 No. 6, pp. 1080-1093.

Schweiger Gallo, I., Keil, A., McCulloch, K.C., Rockstroh, B. and Gollwitzer, P.M. (2009), "Strategic automation of emotion regulation", Journal of Personality and Social Psychology, Vol. 96, pp. 11-31.

Sheeran, P. (2002), "Intention-behavior relations: a conceptual and empirical review”, European Review of Social Psychology, Vol. 12 No. 1, pp. 1-36.

Sheeran, P. and Webb, T.L. (2016), “The intention-behavior gap”, Social and Personality Psychology Compass, Vol. 10 No. 9, pp. 503-518.

Sheldon, O.J. and Fishbach, A. (2011), "Resisting the temptation to compete: self-control promotes cooperation in mixed-motive interactions", Journal of Experimental Social Psychology, Vol. 47 No. 2, pp. 403-410.

Silva, M.A.V., São-João, T.M., Brizon, V.C., Franco, D.H. and Mialhe, F.L. (2018), "Impact of implementation intentions on physical activity practice in adults: a systematic review and metaanalysis of randomized clinical trials", PloS One, Vol. 13 No. 11, e0206294.

Sleesman, D.J., Lennard, A., McNamara, G. and Conlon, D.E. (2017), "Putting escalation of commitment in context: a multi-level review and analysis", Academy of Management Annals, Vol. 12 No. 1, pp. 178-207, doi: 10.5465/annals.2016.0046.

Stasser, G. and Titus, W. (1987), "Effects of information load and percentage of shared information on the dissemination of unshared information during group discussion", Journal of Personality and Social Psychology, Vol. 53 No. 1, pp. 81-93.

Stasser, G., Taylor, L.A. and Hanna, C. (1989), "Information sampling in structured and unstructured discussions of three- and six-person groups", Journal of Personality and Social Psychology, Vol. 57 No. 1, pp. 67-78.

Staw, B.M. (1981), "The escalation of commitment to a course of action", Academy of Management Review, Vol. 6 No. 4, pp. 577-587.

Stoverink, A.C., Kirkman, B.L., Mistry, S. and Rosen, B. (2018), "Bouncing back together: toward a theoretical model of work team resilience", Academy of Management Review, Vol. 45 No. 2, pp. 395-422.

Stroebe, W., van Koningsbruggen, G.M., Papies, E.K. and Aarts, H. (2013), "Why most dieters fail but some succeed: a goal conflict model of eating behavior", Psychological Review, pp. 110-138, doi: 10.1037/a0030849.

Sunstein, C.R. and Hastie, R. (2015), Wiser: Getting beyond Groupthink to Make Groups Smarter, Harvard Business Press, Brighton, MA. 
Thürmer, J.L., McCrea, S.M. and Gollwitzer, P.M. (2013), "Regulating self-defensiveness: if-then plans prevent claiming and creating performance handicaps", Motivation and Emotion, Vol. 37 No. 4, pp. 712-725.

Thürmer, J.L., Wieber, F. and Gollwitzer, P.M. (2015a), "Planning high performance: can groups and teams benefit from implementation intentions?", in Mumford, M.D. and Frese, M. (Eds), The Psychology of Planning in Organizations: Research and Applications, Routledge, New York, NY, pp. 123-145.

Thürmer, J.L., Wieber, F. and Gollwitzer, P.M. (2015b), “A self-regulation perspective on hidden-profile problems: if-then planning to review information improves group decisions", Journal of Behavioral Decision Making, Vol. 28 No. 2, pp. 101-113.

Thürmer, J.L., Wieber, F. and Gollwitzer, P.M. (2017), "Planning and performance in small groups: collective implementation intentions enhance group goal striving", Frontiers in Psychology, Vol. 8 No. 603.

Thürmer, J.L., Wieber, F., Schultze, T. and Schulz-Hardt, S. (2018), "Hidden profile discussion coding", in Brauner, E., Boos, M. and Kolbe, M. (Eds), The Cambridge Handbook of Group Interaction Analysis, Cambridge University Press, Cambridge, pp. 565-574.

Thürmer, J.L., Bieleke, M., Wieber, F. and Gollwitzer, P.M. (2020a), "If-then plans regulate automatic peer-influence on impulse buying”, European Journal of Marketing, Vol. 54 No. 9, pp. 2079-2105.

Thürmer, J.L., Wieber, F. and Gollwitzer, P.M. (2020b), "Strategic self-regulation in groups: collective implementation intentions help cooperate when cooperation is called for", Frontiers in Psychology, Vol. 11, doi: 10.3389/fpsyg.2020.561388.

Tindale, R.S. and Jeremy, R.W. (2020), "Group decision-making”, in Braddick, O. (Ed.), Oxford Research Encyclopedia of Psychology, Oxford University Press, Oxford.

Tindale, R.S. and Kameda, T. (2000), "Social sharedness' as a unifying theme for information processing in groups", Group Processes \& Intergroup Relations, Vol. 3 No. 2, pp. 123-140.

Tindale, R.S. and Sheffey, S. (2002), "Shared information, cognitive load, and group memory", Group Processes \& Intergroup Relations, Vol. 5 No. 1, pp. 5-18.

Toli, A., Webb, T.L. and Hardy, G.E. (2016), "Does forming implementation intentions help people with mental health problems to achieve goals? A meta-analysis of experimental studies with clinical and analogue samples", British Journal of Clinical Psychology, Vol. 55 No. 1, pp. 69-90.

Tosi, H.L., Werner, S., Katz, J.P. and Gomez-Mejia, L.R. (2000), "How much does performance matter? A meta-analysis of CEO pay studies”, Journal of Management, Vol. 26 No. 2, pp. 301-339.

Trötschel, R. and Gollwitzer, P.M. (2007), "Implementation intentions and the willful pursuit of prosocial goals in negotiations", Journal of Experimental Social Psychology, Vol. 43, pp. 579-598, doi: 10.1016/j.jesp.2006.06.002.

Turpin, M.H., Meyers, E.A., Fugelsang, J.A., Friedman, O. and Białek, M. (2019), "Sunk cost bias and withdrawal aversion", The American Journal of Bioethics, Vol. 19 No. 3, pp. 57-59.

Valshtein, T.J., Oettingen, G. and Gollwitzer, P.M. (2020), "Using mental contrasting with implementation intentions to reduce bedtime procrastination: two randomised trials", Psychology and Health, Vol. 35 No. 3, pp. 275-301.

Van Bavel, J.J., Baicker, K., Boggio, P.S., Capraro, V., Cichocka, A., Cikara, M. and Willer, R. (2020), "Using social and behavioural science to support COVID-19 pandemic response", Nature Human Behaviour, Vol. 4 No. 5, pp. 460-471.

van Gelderen, M., Kautonen, T., Wincent, J. and Biniari, M. (2017), "Implementation intentions in the entrepreneurial process: concept, empirical findings, and research agenda”, Small Business Economics. doi: 10.1007/s11187-017-9971-6.

Van Lange, P.A.M., Joireman, J., Parks, C.D. and Van Dijk, E. (2013), "The psychology of social dilemmas: a review", Organizational Behavior and Human Decision Processes, Vol. 120 No. 2, pp. $125-141$. 
$\mathrm{MD}$

58,10

van Mierlo, H. and Kleingeld, A. (2010), "Goals, strategies, and group performance: some limits of goal setting in groups", Small Group Research, Vol. 41 No. 5, pp. 524-555.

Vilà, I., Carrero, I. and Redondo, R. (2017), "Reducing fat intake using implementation intentions: a meta-analytic review", British Journal of Health Psychology, Vol. 22 No. 2, pp. 281-294.

Webb, T.L., Schweiger Gallo, I., Miles, E., Gollwitzer, P.M. and Sheeran, P. (2012), "Effective regulation of affect: an action control perspective on emotion regulation", European Review of Social Psychology, Vol. 23 No. 1, pp. 143-186.

Weber, J.M., Kopelman, S. and Messick, D.M. (2004), "A conceptual review of decision making in social dilemmas: applying a logic of appropriateness", Personality and Social Psychology Review, Vol. 8 No. 3, pp. 281-307.

Weldon, E. and Weingart, L.R. (1993), "Group goals and group performance”, British Journal of Social Psychology, Vol. 32 No. 4, pp. 307-334.

Wieber, F. and Sassenberg, K. (2006), "I can't take my eyes off of it - attention attraction effects of implementation intentions", Social Cognition, Vol. 24 No. 6, pp. 723-752.

Wieber, F., Thürmer, J.L. and Gollwitzer, P.M. (2012), "Collective action control by goals and plans: applying a self-regulation perspective to group performance", American Journal of Psychology, Vol. 125 No. 3, pp. 275-290.

Wieber, F., Gollwitzer, P.M. and Sheeran, P. (2014), "Strategic regulation of mimicry effects by implementation intentions", Journal of Experimental Social Psychology, Vol. 53, pp. 31-39.

Wieber, F., Thürmer, J.L. and Gollwitzer, P.M. (2015a), "Attenuating the escalation of commitment to a faltering project in decision-making groups: an implementation intention approach", Social Psychological and Personality Science, Vol. 6 No. 5, pp. 587-595.

Wieber, F., Thürmer, J.L. and Gollwitzer, P.M. (2015b), "Promoting the translation of intentions into action by implementation intentions: behavioral effects and physiological correlates", Frontiers in Human Neuroscience, Vol. 9.

Wildschut, T. and Insko, C.A. (2007), "Explanations of interindividual - intergroup discontinuity: a review of the evidence", European Review of Social Psychology, Vol. 18 No. 1, pp. 175-211.

Wildschut, T., Pinter, B., Vevea, J.L., Insko, C.A. and Schopler, J. (2003), "Beyond the group mind: a quantitative review of the interindividual-intergroup discontinuity effect", Psychological Bulletin, Vol. 129 No. 5, pp. 698-722.

Wilson, S. (2020), "Pandemic leadership: lessons from New Zealand's approach to COVID-19", Leadership, Vol. 16 No. 3, pp. 279-293.

Witte, E.H. (1989), "Köhler rediscovered: the anti-Ringelmann effect", European Journal of Social Psychology, Vol. 19 No. 2, pp. 147-154.

Woolley, A.W., Gerbasi, M.E., Chabris, C.F., Kosslyn, S.M. and Hackman, J.R. (2008), "Bringing in the experts: how team composition and collaborative planning jointly shape analytic effectiveness", Small Group Research, Vol. 39 No. 3, pp. 352-371.

\section{Corresponding author}

J. Lukas Thürmer can be contacted at: lukas.thuermer@sbg.ac.at

For instructions on how to order reprints of this article, please visit our website:

www.emeraldgrouppublishing.com/licensing/reprints.htm

Or contact us for further details: permissions@emeraldinsight.com 